\title{
Optimizing sample pretreatment for compound-specific stable carbon isotopic analysis of amino sugars in marine sediment
}

\author{
R. Zhu ${ }^{1}$, Y.-S. Lin ${ }^{1,2}$, J. S. Lipp ${ }^{1}$, T. B. Meador ${ }^{1}$, and K.-U. Hinrichs ${ }^{1}$ \\ ${ }^{1}$ Organic Geochemistry Group, MARUM-Center for Marine Environmental Sciences \& Department of Geosciences, \\ University of Bremen, 28359 Bremen, Germany \\ ${ }^{2}$ Department of Oceanography, National Sun Yat-Sen University, No. 70 Lienhai Rd, Kaohsiung 804, Taiwan
}

Correspondence to: R. Zhu (rongzhu1018@gmail.com)

Received: 28 November 2013 - Published in Biogeosciences Discuss.: 9 January 2014

Revised: 22 June 2014 - Accepted: 8 July 2014 - Published: 11 September 2014

\begin{abstract}
Amino sugars are quantitatively significant constituents of soil and marine sediment, but their sources and turnover in environmental samples remain poorly understood. The stable carbon isotopic composition of amino sugars can provide information on the lifestyles of their source organisms and can be monitored during incubations with labeled substrates to estimate the turnover rates of microbial populations. However, until now, such investigation has been carried out only with soil samples, partly because of the much lower abundance of amino sugars in marine environments. We therefore optimized a procedure for compoundspecific isotopic analysis of amino sugars in marine sediment, employing gas chromatography-isotope ratio mass spectrometry. The whole procedure consisted of hydrolysis, neutralization, enrichment, and derivatization of amino sugars. Except for the derivatization step, the protocol introduced negligible isotopic fractionation, and the minimum requirement of amino sugar for isotopic analysis was $20 \mathrm{ng}$, i.e., equivalent to $\sim 8 \mathrm{ng}$ of amino sugar carbon. Compoundspecific stable carbon isotopic analysis of amino sugars obtained from marine sediment extracts indicated that glucosamine and galactosamine were mainly derived from organic detritus, whereas muramic acid showed isotopic imprints from indigenous bacterial activities. The $\delta^{13} \mathrm{C}$ analysis of amino sugars provides a valuable addition to the biomarker-based characterization of microbial metabolism in the deep marine biosphere, which so far has been lipid oriented and biased towards the detection of archaeal signals.
\end{abstract}

\section{Introduction}

Amino sugars are significant sedimentary components that are mostly derived from microorganisms and invertebrates. For example, the four major amino sugars, glucosamine $(\mathrm{GlcN})$, galactosamine $(\mathrm{GalN})$, mannosamine $(\mathrm{ManN})$ and muramic acid (MurA), accounted for up to $12 \%$ of total organic carbon (TOC) in grassland soils in North America (Amelung et al., 1999) and $\sim 2 \%$ of TOC in coastal Peruvian surface sediments (Niggemann and Schubert, 2006). Amino sugars are preserved in the form of biopolymers such as peptidoglycan, chitin, and lipopolysaccharides. Because of the minor contribution of amino sugars from meso- and macro-organisms (Simpson et al., 2004), the proportion of amino sugar-derived $\mathrm{C}$ in the total $\mathrm{C}$ pool has been used frequently as a proxy for microbial contributions to soil organic matter, and the ratios between different amino sugars have been employed as indicators of microbial community compositions (e.g., Guggenberger et al., 1999; Zhang et al., 1999; Amelung, 2001; Glaser et al., 2004). In marine environments, amino sugars could be derived from microbes, phytoplankton and animals. Prokaryotic biomass is thought to be the major source of GlcN and GalN in marine sediment (e.g., Niggemann and Schubert, 2006; Langerhuus et al., 2012) and seawater (Benner and Kaiser, 2003); however, most amino sugars in seawater are not likely associated with peptidoglycan (Aluwihare et al., 2005; Aluwihare and Meador, 2008). Planktonic bacterial sources may contribute to the sedimentary MurA pool, and thus may complicate the use of MurA as a biomarker for sedimentary bacteria. Recently, the investigation of amino sugars has been extended to the marine deep 
biosphere by Lomstein et al. (2012), who used MurA as a tool for indirectly quantifying endospores in subseafloor sediment.

The stable carbon isotopic composition $\left(\delta^{13} \mathrm{C}\right)$ of individual cellular biomarkers can reveal the carbon metabolism and/or lifestyles of the source organisms in natural environments (e.g., Lin et al., 2010; Schubotz et al., 2011), and incubations with ${ }^{13} \mathrm{C}$-labeled substrates have been used to probe microbial communities by tracking the production of labeled biomarkers over time (e.g., Veuger et al., 2006; Kellermann et al., 2012; Lin et al., 2013). The latter technique has been widely employed in soil science to investigate the formation and/or turnover kinetics of amino sugars (e.g., Glaser et al., 2005; Decock et al., 2009; Bai et al., 2012). However, to date, the isotopic composition of amino sugars in marine sediment remains poorly explored, partly because of the much lower concentration of amino sugars in marine sediment compared to soil, which results in the need for an efficient pretreatment procedure to enable precise isotopic determination.

Compound-specific $\delta^{13} \mathrm{C}$ analysis of amino sugars is commonly performed via isotope ratio mass spectrometry (IRMS) after separation of compounds by either gas chromatography (GC; Glaser and Gross, 2005), liquid chromatography (LC; Bodé et al., 2009) or, more recently, ion chromatography (IC; Dippold et al., 2014). Compared with LC-IRMS, the GC-based method is less sensitive to adverse effects of the sample matrix on detection (McCullagh, 2010; Morrison et al., 2010; Rinne et al., 2012), and requires smaller amounts of amino sugars. The accuracy and precision of the GC-based method, though compromised by the introduction of carbon during derivatization (Glaser and Gross, 2005), has been shown to sufficiently resolve molecular isotopic differences caused by diverse biogeochemical processes in marine sediments (cf. Lin et al., 2010). Therefore, we consider GC-IRMS an attractive alternative to LCIRMS for the isotopic analysis of amino sugars in deep marine sediments. A substantial effort has been made during the past few decades to optimize the pretreatment procedure for GC-based quantification of amino sugars, which requires three major steps: acid hydrolysis, purification, and derivatization, with hydrolysis being the key step for releasing amino sugars from biopolymers. Besides the most frequently used hydrolysis protocol, namely $6 \mathrm{M}$ hot hydrochloric acid (HCl; Zhang and Amelung, 1996), less destructive procedures involving either hot trifluoroacetic acid (TFA; Neeser and Schweizer, 1984) or sulfuric acid $\left(\mathrm{H}_{2} \mathrm{SO}_{4}\right.$; Fox et al., 1983) have been proposed for the simultaneous extraction of neutral and amino sugars. Different purification protocols, such as neutralization with a base solution (Zhang and Amelung, 1996), precipitation of excess acid (Cowie and Hedges, 1984; Neeser and Schweizer, 1984), and deionization of hydrolysate (Cowie and Hedges, 1984), to name a few, have been used to reduce the content of acid and salts that are known to interfere with amino sugar derivatization. Conversion of amino sugars for $\mathrm{GC}$ analysis has been achieved via derivatization into alditol acetates (AA; Fox et al., 1983), aldononitrile acetates (ANA; Guerrant and Moss, 1984), or $O$-methyloxime acetates (Neeser and Schweizer, 1984). However, to perform isotopic analysis of amino sugars at trace levels, a systematic evaluation of these various methods with regard to the product recovery and pretreatment reproducibility is necessary.

The goal of this study is to devise a pretreatment protocol for GC-based isotopic analysis of amino sugars in subseafloor sediments. Since deep sediment samples are generally severely limited in size and often contain substantially lower TOC than surface sediments, a protocol for sensitive isotopic analysis of amino sugars in trace amounts is critical. Hence, we tackled three major analytical tasks. (1) We systematically evaluated existing pretreatment methods for amino sugar analysis to select the method that gave the highest recoveries of products from marine sediments. (2) We introduced the use of a new type of solid-phase extraction (SPE) into the pretreatment protocol and demonstrated enhanced recoveries compared with existing methods. (3) We developed a preparative high-performance liquid chromatography (HPLC) method to enrich amino sugars to a desired concentration for proper isotopic assessment. We then applied our protocol to determine the stable carbon isotopic compositions of amino sugars from the selected subseafloor sediment samples.

\section{Experimental}

\subsection{Standards and environmental samples}

The amino sugar standards, derivatization reagents, and all other chemicals used in this study were purchased from Sigma-Aldrich Chemie GmbH (Munich, Germany) or Merck KGaA (Darmstadt, Germany). The Supelclean ${ }^{\mathrm{TM}}$ ENVI$\mathrm{Carb}^{\mathrm{TM}}$ Plus SPE cartridges and accessories were obtained from Sigma-Aldrich Chemie GmbH or Carl Roth $\mathrm{GmbH}$ (Karlsruhe, Germany).

A batch of surface sediment for method optimization was collected from the upper tidal flat of the Wadden Sea near Wremen, Germany, in February $2010\left(53^{\circ} 38^{\prime} 0\right.$ N, $8^{\circ} 29^{\prime} 30 \mathrm{E}$ ). In addition, four marine sediment samples of different types were selected for stable carbon isotopic analysis of individual amino sugars. The seep sample was recovered from the continental margin off Pakistan (site GeoB 12315-9, 1-2 cm below the seafloor, cmbsf) during RV Meteor cruise M74/3 in November 2007. It was located within the lower part of the oxygen minimum zone and associated with dense microbial mats from sulfide-oxidizing bacteria (Fischer et al., 2012). Two subseafloor samples were retrieved from the Marmara Sea (site GeoB 15104-2) and the Black Sea (site GeoB 15105-2) during RV Meteor cruise M84/1 (DARCSEAS) in February 2011 (Zabel et al., 2013). The sample from the Marmara Sea was collected at $2.88 \mathrm{mbsf}$ 
and was located in a sapropel layer deposited under suboxic bottom-water conditions (Çağatay et al., 2000). The Black Sea sample was collected at $1.57 \mathrm{mbsf}$, where the sediment was highly diluted by terrigenous components and showed a lack of bioturbation. The deepest sediment sample was recovered from the Peru Margin (Ocean Drilling Program leg 201, 1229A-3H-2, 16.6 mbsf), and had a high TOC content $(3.8 \%)$.

\subsection{Hydrolysis tests}

Hydrolysis tests were performed in triplicate in $40 \mathrm{ml}$ glass tubes by adding different acids to $\sim 5 \mathrm{~g}$ of freeze-dried Wadden Sea sediment. The tubes were filled with nitrogen before being sealed with Teflon-coated screw caps to prevent oxidation of sugars at high temperature during hydrolysis. The evaluated hydrolytic conditions were as follows.

1. The sample was kept at room temperature for $2 \mathrm{~h}$ after the addition of $12 \mathrm{M} \mathrm{H}_{2} \mathrm{SO}_{4}$, followed by dilution to $1.2 \mathrm{M} \mathrm{H}_{2} \mathrm{SO}_{4}$ and heating at $105^{\circ} \mathrm{C}$ for $3 \mathrm{~h}$ (modified from Cowie and Hedges, 1984).

2. The sample was hydrolyzed with $4 \mathrm{M}$ TFA at $105^{\circ} \mathrm{C}$ for $4 \mathrm{~h}$ (Amelung et al., 1996).

3. The sample was treated with $6 \mathrm{M} \mathrm{HCl}$ at $105^{\circ} \mathrm{C}$ for $8 \mathrm{~h}$ (Zhang and Amelung, 1996).

After hydrolysis, the samples were cooled to room temperature, spiked with $100 \mu \mathrm{g}$ of myo-inositol as an internal standard, and centrifuged at $800 \times g$ for $5 \mathrm{~min}$. After being passed through combusted glass microfiber filters $(\mathrm{GF} / \mathrm{F}, 70 \mathrm{~mm} \Phi$, Whatman $^{\mathrm{TM}}$ ), the hydrolysates obtained from treatments (2) and (3) were evaporated to dryness with a rotary evaporator $\left(45^{\circ} \mathrm{C}\right.$, under vacuum) and re-dissolved in $4 \mathrm{ml}$ of MilliQ water.

\subsection{Neutralization and desalting}

Samples hydrolyzed with $\mathrm{H}_{2} \mathrm{SO}_{4}$ were neutralized by adding finely ground barium hydroxide $\left(\mathrm{Ba}(\mathrm{OH})_{2} ;\right.$ Cowie and Hedges, 1984), whereas TFA-treated samples were freezedried overnight to remove the acid. Hydrolysates liberated with $\mathrm{HCl}$ were initially subjected to the procedure described by Zhang and Amelung (1996), with slight modification. The acidic solution was adjusted to $\mathrm{pH}$ 6.5-7.0 with $1 \mathrm{M}$ potassium hydroxide $(\mathrm{KOH})$ and centrifuged to remove the precipitates. The supernatant was evaporated to dryness under $\mathrm{N}_{2}$, the condensates were re-dissolved in $2 \mathrm{ml}$ methanol $(\mathrm{MeOH})$, and amino sugars were collected in the supernatant after centrifugation. Because treatments with $\mathrm{HCl}$ gave the best recoveries (see below), we went on to explore other neutralization and desalting methods that are compatible with $\mathrm{HCl}$. A standard mixture containing $20 \mu \mathrm{g}$ of each amino sugar was treated with $1 \mathrm{ml}$ of $6 \mathrm{M} \mathrm{HCl}$, and the following three methods were performed in triplicate to compare the yields with those of Zhang and Amelung (1996).
1. Silver carbonate $\left(\mathrm{Ag}_{2} \mathrm{CO}_{3}\right)$ was added gradually to the mixture to neutralize the $\mathrm{HCl}$. The silver chloride $(\mathrm{AgCl})$ precipitate was removed by centrifugation (cf. Neeser and Schweizer, 1984).

2. After neutralization with a $1 \mathrm{M} \mathrm{KOH}$ solution, the mixture was desalted by percolating the solution through a glass column filled with $3 \mathrm{~g}$ of pre-conditioned Dowex 50WX8 cation exchange resin (100-200 mesh, $\mathrm{H}^{+}$ form), as described by Amelung et al. (1996). The column was washed with $10 \mathrm{ml}$ of MilliQ water to remove excess salts, and amino sugars were subsequently eluted with $10 \mathrm{ml}$ of $2 \mathrm{M}$ ammonium hydroxide $\left(\mathrm{NH}_{4} \mathrm{OH}\right)$.

3. We evaluated for the first time the applicability of Supelclean $^{\mathrm{TM}}$ ENVI-Carb ${ }^{\mathrm{TM}}$ Plus SPE cartridges in carbohydrate analysis. ENVI-Carb ${ }^{\mathrm{TM}}$ Plus is a microporous amorphous carbon molecular sieve developed for the extraction of highly polar compounds from water. Its predecessor, Supelclean ${ }^{\mathrm{TM}}$ ENVI-Carb ${ }^{\mathrm{TM}}$, has been used to extract oligosaccharides in aqueous samples (Itoh et al., 2002). Prior to use, the SPE cartridge was preconditioned sequentially with $10 \mathrm{ml}$ methylene chloride (DCM), $20 \mathrm{ml} \mathrm{MeOH}$, and $15 \mathrm{ml}$ MilliQ water. The hydrolysate containing amino sugars was neutralized with $1 \mathrm{M} \mathrm{KOH}$ and desalted by pulling through the SPE cartridge coupled with an SPE manifold (Carl Roth $\mathrm{GmbH}$, Karlsruhe, Germany) under vacuum. The SPE cartridge was then dried for $10 \mathrm{~min}$ and eluted under vacuum in the reversed direction with $5 \mathrm{ml} \mathrm{MeOH}$, followed by $5 \mathrm{ml} \mathrm{DCM} / \mathrm{MeOH}(1: 1, v: v)$ to recover the amino sugars.

All the desalted products were evaporated under a stream of $\mathrm{N}_{2}$, lyophilized overnight, and converted to GC-amenable derivatives for analysis. Quantities and recoveries of individual amino sugars were determined via calibration curves that were generated from pure standards. The Wadden Sea sediment was also used to assess the efficiencies of the neutralization and desalting methods for environmental samples.

\subsection{Derivatization and purification}

Amino sugar standards were transformed to alditol acetate (AA) or aldononitrile acetate (ANA) derivatives in triplicate following the methods of Fox et al. (1983) or Guerrant and Moss (1984), respectively. After being converted to ANA derivatives, amino sugars extracted from the environmental samples were further purified with a self-packed silica gel column (0.5 g; Kieselgel, 0.06-0.2 mm; Carl Roth $\mathrm{GmbH}$, Karlsruhe, Germany; cf. Lin et al., 2010). The best recovery ( $>95 \%$ of each amino sugar as an ANA derivative) was achieved by elution with $8 \mathrm{ml}$ hexane/ethyl acetate $(1: 4, v: v)$. The eluent was evaporated to dryness under a $\mathrm{N}_{2}$ stream and re-dissolved in hexane/ethyl acetate $(1: 1, v: v)$ prior to analysis. 


\subsection{Preparation of amino sugar-enriched fractions by preparative HPLC}

For samples containing low concentrations of amino sugars and/or elevated sedimentary matrices, amino sugar extracts were separated and enriched via preparative HPLC. A mixture of amino sugar standards and desalted hydrolysate of the Wadden Sea sediment sample were employed to develop the preparation protocol. The sample was re-dissolved in acetonitrile $(\mathrm{ACN}) / \mathrm{H}_{2} \mathrm{O}(7: 3$, $v: v$ ) prior to injection. The flow rate was $1 \mathrm{ml} \mathrm{min}^{-1}$, and the eluent gradient ramped steadily from $100 \%$ eluent A to $100 \%$ eluent B over $15 \mathrm{~min}$, then held at $100 \%$ eluent $\mathrm{B}$ for $15 \mathrm{~min}$, followed by $10 \mathrm{~min}$ reequilibration with $100 \%$ eluent $\mathrm{A}$. Eluent $\mathrm{A}$ was composed of $\mathrm{ACN} / \mathrm{H}_{2} \mathrm{O} / \mathrm{NH}_{4} \mathrm{OH} /$ formic acid $(90: 10: 0.1: 0.2, v$ : $v: v: v$ ); eluent $\mathrm{B}$ was $\mathrm{ACN} / \mathrm{H}_{2} \mathrm{O} / \mathrm{NH}_{4} \mathrm{OH} /$ formic acid $(30: 70: 0.1: 0.2, v: v: v: v)$. Amino sugars were thereafter separated into two fractions, the first $(\mathrm{F} 1 ; 5.0-7.6 \mathrm{~min})$ containing the three basic amino sugars, and the second (F2; 7.6-9.6 min) MurA. Fractions collected during preparative HPLC were evaporated to dryness and converted to GCamenable derivatives to monitor separation efficiency and the isotopic fractionation effect. With this method, we also obtained the ManN-free and MurA-free sedimentary matrices (i.e., F2 and F1, respectively), which were used to determine the accessible amino sugar concentrations for isotopic analysis (see below).

\subsection{Accessible amino sugar concentrations for GC-IRMS analysis}

To determine the accessible concentration range of amino sugars for compound-specific $\delta^{13} \mathrm{C}$ analysis, $10-140 \mathrm{ng}$ of the two minor amino sugars found in natural marine environments (i.e., ManN and MurA) were converted to ANA derivatives and injected as pure standards into the GC-IRMS in triplicate. Additionally, pure ManN or MurA was spiked to the ManN-free or MurA-free sedimentary matrix, to validate the $\delta^{13} \mathrm{C}$ values for realistic conditions. These sedimentary matrices were obtained from the preparative HPLC separation of the Peru Margin sample. Monitored by GC-mass spectrometry (MS) in selective ion monitoring (SIM) mode, the concentration of the corresponding analyte in the matrix was below the detection limit $(<0.05 \mathrm{ng}$ on column).

\subsection{Instrumentation}

Quantification of amino sugars was accomplished using an Agilent 6890N GC instrument coupled to an Agilent 5973 inert Mass Selective Detector (MSD) with an electron impact (EI) source, whereas compound-specific isotopic analysis of amino sugars was performed with a Trace GC Ultra instrument coupled to a Delta Plus XP isotope ratio mass spectrometer via Combustion Interface III (Thermo Finni- gan MAT GmbH, Bremen, Germany). Two columns with different polarities, an Optima 17MS column $(30 \mathrm{~m} \times 0.25 \mathrm{~mm}$, $0.25 \mu \mathrm{m}$ film thickness; Macherey-Nagel GmbH \& Co. KG, Düren, Germany) and an Rxi-5ms column $(30 \mathrm{~m} \times 0.25 \mathrm{~mm}$, $0.25 \mu \mathrm{m}$ film thickness; Restek GmbH, Bad Homburg, Germany), were applied to optimize the separation of sugar derivatives.

The ANA method produced the most stable derivatives and satisfying results (see below); the corresponding GC operation conditions were specified here in detail. Separation of ANA derivatives in the Optima 17MS column was modified from Glaser and Gross (2005). The injector temperature was $250^{\circ} \mathrm{C}$, and helium was used as a carrier gas at a constant flow rate of $1 \mathrm{ml} \mathrm{min}^{-1}$. The $\mathrm{GC}$ temperature program was initiated at $80^{\circ} \mathrm{C}$ and held for $4 \mathrm{~min}$, then increased to $250^{\circ} \mathrm{C}$ at $30^{\circ} \mathrm{C} \mathrm{min}^{-1}$ and held for $10 \mathrm{~min}$, and finally raised to $280^{\circ} \mathrm{C}$ at $3{ }^{\circ} \mathrm{C} \mathrm{min}^{-1}$ and held for $5 \mathrm{~min}$. The GC parameters for the Rxi-5ms column were as follows: injector temperature, $250{ }^{\circ} \mathrm{C}$; carrier gas, helium; flow rate, $1.1 \mathrm{ml} \mathrm{min}^{-1}$. The oven temperature was kept at $70^{\circ} \mathrm{C}$ for $1 \mathrm{~min}$, ramped up to $230^{\circ} \mathrm{C}$ at $20^{\circ} \mathrm{C} \mathrm{min}^{-1}$, held for $20 \mathrm{~min}$, and further increased at $20^{\circ} \mathrm{C} \mathrm{min}^{-1}$ to $300^{\circ} \mathrm{C}$ and held for $5 \mathrm{~min}$. The mass spectrometer was programmed in SIM mode to target specific mass fragment ions of the derivatives for quantification. The selected ions were $m / z 187$ and 289 for GlcN, GalN and ManN, and $m / z 236$ and 356 for MurA.

Separation and detection of amino sugars were achieved with an Agilent 6130 MSD single quadrupole mass spectrometer coupled to an Agilent 1200 Series HPLC system via a multimode ion source in electrospray ionization mode (Agilent Technologies Deutschland GmbH, Böblingen, Germany) equipped with an Econosphere $\mathrm{NH}_{2}$ column $(250 \mathrm{~mm} \times 4.6 \mathrm{~mm}, 5 \mathrm{~mm}$ particle size; Alltech Associates Inc., Deerfield, IL, USA).

Stable carbon isotopic compositions of the pure amino sugars, internal standards and the acetylation reagent were determined independently by a Flash 2000 organic elemental analyzer coupled to a Delta V Plus isotope ratio mass spectrometer (EA-IRMS) via a ConFlo IV interface (Thermo Finnigan MAT GmbH). The EA-IRMS was operated in C, $\mathrm{N}$ mode and controlled by the Finnigan Isodat 3.0 software. The oxidation and reduction reactors were heated to $999^{\circ} \mathrm{C}$ and $680^{\circ} \mathrm{C}$, respectively. Helium was used as a carrier gas at a flow rate of $100 \mathrm{ml} \mathrm{min}^{-1}$, while the oxidation reagent oxygen had a flow rate of $200 \mathrm{ml} \mathrm{min}^{-1}$. The $\mathrm{CO}_{2}$ reference gas pulse was introduced two times $(20 \mathrm{~s}$ each) at the beginning of each run. Quadruplicate measurements by EA-IRMS generated highly accurate $\delta^{13} \mathrm{C}$ values of each compound.

\subsection{Calculations}

Isotopic compositions were expressed using the $\delta$ notation: $\delta^{13} \mathrm{C}=\left(R_{\text {sample }} / R_{\text {standard }}-1\right) \times 1000 \%$, with $R={ }^{13} \mathrm{C} /{ }^{12} \mathrm{C}$ and $R_{\text {standard }}=0.011180 \pm 0.0000028$; the reference standard was Vienna Pee Dee Belemnite. We determined the isotopic 
Table 1. Amino sugars liberated from surface sediment by different hydrolytic procedures. The sample used in this test was collected from the Wadden Sea. All the amino sugars were quantified by GC-MS in SIM mode and are shown as concentration \pm standard deviation $(n=3)$; the ions selected for detection were $m / z, 187$ and 289 for GlcN, GalN and ManN, and $m / z 236$ and 356 for MurA.

\begin{tabular}{llllll}
\hline Hydrolysis and neutralization methods & Reference & $\begin{array}{l}\text { GlcN } \\
\left(\mu g^{-1} \mathrm{dw}\right)\end{array}$ & $\begin{array}{l}\text { GalN } \\
\left(\mu \mathrm{gg}^{-1} \mathrm{dw}\right)\end{array}$ & $\begin{array}{l}\text { ManN } \\
\left(\mu \mathrm{gg} \mathrm{g}^{-1} \mathrm{dw}\right)\end{array}$ & $\begin{array}{l}\text { MurA } \\
\left(\mu \mathrm{gg}^{-1} \mathrm{dw}\right)\end{array}$ \\
\hline $12 \mathrm{M} \mathrm{H}_{2} \mathrm{SO}_{4}-1.2 \mathrm{M} \mathrm{H}_{2} \mathrm{SO}_{4} ; \mathrm{Ba}(\mathrm{OH})_{2}$ & Cowie and Hedges (1984) & $8.8 \pm 1.1$ & $4.7 \pm 0.8$ & $0.7 \pm 0.1$ & $0.1 \pm 0.2$ \\
$4 \mathrm{M} \mathrm{TFA} ; 105^{\circ} \mathrm{C}, 4 \mathrm{~h} ;$ evaporation & Amelung et al. (1996) & $1.2 \pm 0.1$ & $1.0 \pm 0.4$ & $0.3 \pm 0.5$ & $0.2 \pm 0.1$ \\
$6 \mathrm{M} \mathrm{HCl} ; 105^{\circ} \mathrm{C}, 8 \mathrm{~h} ; \mathrm{KOH}-\mathrm{MeOH}$ & Zhang and Amelung (1996) & $17.6 \pm 0.8$ & $15.7 \pm 0.6$ & $1.5 \pm 0.2$ & $0.5 \pm 0.2$ \\
$6 \mathrm{M} \mathrm{HCl} ; 105^{\circ} \mathrm{C}, 8 \mathrm{~h} ; \mathrm{KOH}-\mathrm{SPE}$ & This study & $34.8 \pm 0.3$ & $26.0 \pm 0.7$ & $2.2 \pm 0.3$ & $0.7 \pm 0.02$ \\
\hline
\end{tabular}

Abbreviations: GlcN, glucosamine; GalN, galactosamine; ManN, mannosamine; MurA, muramic acid.

Table 2. Recoveries and standard deviations of HCl-treated amino sugar standards after different neutralization and desalting procedures $(n=3)$.

\begin{tabular}{clllll}
\hline Methods & Reference & GlcN (\%) & GalN (\%) & ManN (\%) & MurA $(\%)$ \\
\hline $\mathrm{KOH}-\mathrm{MeOH}$ & Zhang and Amelung (1996) & $95.4 \pm 4.7$ & $86.5 \pm 4.2$ & $77.3 \pm 9.6$ & $97.8 \pm 10.7$ \\
$\mathrm{Ag}_{2} \mathrm{CO}_{3}$ & Neeser and Schweizer (1984) & $26.4 \pm 6.7$ & $12.0 \pm 1.0$ & $82.8 \pm 6.4$ & $7.0 \pm 0.6$ \\
Dowex 50WX8 $\mathrm{H}_{2} \mathrm{O}$ & Amelung et al. (1996) & $7.0 \pm 1.5$ & $8.7 \pm 1.9$ & $8.5 \pm 1.8$ & $7.1 \pm 0.2$ \\
Dowex 50WX8 $\quad \mathrm{NH}_{4} \mathrm{OH}$ & Amelung et al. (1996) & $104.5 \pm 29.9$ & $63.7 \pm 23.9$ & $71.6 \pm 23.7$ & $107.7 \pm 28.5$ \\
$\mathrm{KOH}-\mathrm{SPE}$ & Our proposed method & $103.6 \pm 6.6$ & $92.7 \pm 5.5$ & $89.4 \pm 4.9$ & $95.0 \pm 2.4$
\end{tabular}

values only for ANA derivatives of amino sugars, which exhibited the highest yields. The $\delta^{13} \mathrm{C}$ values and the corresponding standard deviations $\left(s_{\text {Total }}\right)$ of individual amino sugars were calculated following the procedure described by Glaser and Gross (2005), with a slight modification. 3- $O$ methyl-D-glucopyranose (3-O-Me-Glc) was applied as an internal standard to correct the isotopic fractionation that is known to occur during acetylation of the hydroxyl groups (Lin et al., 2010). A compound-specific factor $F$ to correct for fractionation during derivatization was introduced by Glaser and Gross (2005, Eq. 1).

$$
\begin{aligned}
& F=\delta^{13} \mathrm{C}_{\text {Der }} \times N_{\text {Der }}-\delta^{13} \mathrm{C}_{\text {AS }} \times N_{\text {AS }} \\
& -\delta^{13} \mathrm{C}_{\text {Acet }} \times N_{\text {Acet }},
\end{aligned}
$$

where $N$ is the number of $\mathrm{C}$ atoms of the amino sugar derivative $\left(N_{\text {Der }}\right)$, the original amino sugar $\left(N_{\mathrm{AS}}\right)$, and the acetyl group $\left(N_{\text {Acet }}\right)$ of acetic anhydride used for derivatization. We determined the $F$ factor experimentally using ANA derivatives of seven external standard solutions in the concentration range of 1-20 $\mu \mathrm{g}$ per batch for ManN and MurA, and 1-60 $\mu \mathrm{g}$ per batch for the other standards.

\section{Results and discussion}

\subsection{Hydrolytic conditions for releasing amino sugar monomers}

Table 1 summarizes the results of the hydrolysis tests. Hydrolysis with $6 \mathrm{M} \mathrm{HCl}$ provided the highest recoveries of amino sugars from the Wadden Sea surface sediment sample, followed by $\mathrm{H}_{2} \mathrm{SO}_{4}$ and TFA. GlcN and GalN were the most abundant amino sugars, with concentrations being one order of magnitude higher than those of ManN and MurA. Based on these results, further work aimed to optimize the neutralization and desalting steps that followed the hot $\mathrm{HCl}$ treatment. We observed that the $\mathrm{HCl}$ method yielded lower recoveries of neutral sugars compared with the other two protocols (data not shown), a result in agreement with the previous finding of Amelung et al. (1996), and suggesting the occurrence of a dehydration reaction between $\mathrm{HCl}$ and the monosaccharides.

\subsection{Comparison of neutralization and desalting methods after hydrolysis by $\mathrm{HCl}$}

Recoveries of amino sugar standards ranged from 77 to $98 \%$ using the procedure proposed by Zhang and Amelung (1996), i.e., neutralization with $1 \mathrm{M} \mathrm{KOH}$ and desalting with $\mathrm{MeOH}$ (Table 2). We did not observe significant differences in amino sugar recoveries using standard compounds after employing either the ENVI-Carb ${ }^{\mathrm{TM}}$ Plus SPE cartridge or the method described by Zhang and Amelung (1996). However, for the surface sediment sample, recoveries using the former method exceeded those of the latter by factors of 1.5 to 2 (Table 1), suggesting that the SPE method is less sensitive to the presence of sedimentary matrices. Moreover, we noted that the SPE cartridge allowed for excellent recoveries of neutral hexoses such as glucose, galactose, and mannose (data not shown). 
Table 3. Recoveries and $\delta^{13} \mathrm{C}$ values of amino sugar standards after separation by preparative HPLC. Standard deviations of GC-IRMS measurements $\left(s_{\mathrm{GC}}\right)$ are reported for individual amino sugars, and the total analytical error of $\delta^{13} \mathrm{C}$ values $\left(s_{\text {Total }}\right)$ was calculated according to error propagation $(n=3)$.

\begin{tabular}{llllll}
\hline \multirow{2}{*}{ Fraction } & \multirow{2}{*}{ Amino sugars } & \multirow{2}{*}{ Recovery $(\%)$} & \multicolumn{4}{c}{ GC-IRMS } \\
& & & $\delta^{13} \mathrm{C}_{\mathrm{AS}, \mathrm{GC}}(\% \circ)$ & $s_{\mathrm{GC}}(\% \circ)$ & $s_{\text {Total }}(\%$ ) \\
\hline \multirow{3}{*}{1} & GlcN & $86.6 \pm 1.5$ & -20.6 & 0.26 & 1.57 \\
& GalN & $113.8 \pm 3.0$ & -20.1 & 0.36 & 1.73 \\
& ManN & $70.8 \pm 2.8$ & -19.8 & 0.75 & 1.44 \\
\hline \multirow{2}{*}{2} & MurA & $105.8 \pm 6.7$ & -20.9 & 0.35 & 1.02 \\
\hline
\end{tabular}

The other two methods tested in this study yielded less satisfying results. $\mathrm{Ag}_{2} \mathrm{CO}_{3}$ reacts with $\mathrm{HCl}$ to form $\mathrm{CO}_{2}$ and $\mathrm{AgCl}$, which has very low solubility in water and eliminates the need for a desalting step. However, with the exception of ManN, major losses of amino sugars were observed (Table 2), presumably owing to interactions between amino sugars and the $\mathrm{AgCl}-\mathrm{Ag}_{2} \mathrm{CO}_{3}$ mixture. Cation exchange using the Dowex 50WX8 cation exchange resin allows for the separation of amino sugars (in the $\mathrm{NH}_{4} \mathrm{OH}$ fraction) from neutral sugars (in the $\mathrm{H}_{2} \mathrm{O}$ fraction). Recoveries of amino sugars by this method were highly variable (Table 2), partly because of the incomplete evaporation of $\mathrm{NH}_{4} \mathrm{OH}$, which might affect the efficiency of ANA derivatization. Nevertheless, further evaluation should be performed in future work using a recently optimized cation exchange-based procedure (Indorf et al., 2013).

\subsection{Derivatization of amino sugars}

Although the AA derivatization method has been employed previously to investigate amino sugars (Fox et al., 1995, 1996), it was rather time consuming ( $~ 1 \mathrm{~d}$; cf. Fox et al., 1983), and the derivative of MurA exhibited poor stability compared with the corresponding basic amino sugar derivatives (data not shown). The addition of $N$-methylimidazole as a catalyst helped to accelerate the acetylation of basic amino sugars, but it failed to produce an appreciable signal peak for the MurA derivative (Whiton et al., 1985). By contrast, the acetylation time of the ANA derivatization method was reasonably low $(20 \mathrm{~min})$, and the derivatives remained stable at $-20^{\circ} \mathrm{C}$ for up to $1 \mathrm{yr}$, as confirmed by repeated injections of amino sugar ANA derivatives over the course of 12 months (data not shown). Such long-term stability of derivatives is essential for isotope determination. Each amino sugar, including MurA, yielded a single, well-resolved chromatographic peak during GC analysis, with either an Rxi$5 \mathrm{~ms}$ or an Optima 17MS column, when the injected amount was less than $120 \mathrm{ng}$ per amino sugar. We therefore concluded that the ANA method was superior to the AA approach for GC-based analysis of amino sugars, and subsequently implemented this step in our method optimization. Like Glaser and Gross (2005), we also noted that the elu- tion order of ANA derivatives differed between the two GC columns (Fig. 1a, b). The availability of two alternative separations was advantageous for determining the $\delta^{13} \mathrm{C}$ values of the minor components, which co-eluted with major peaks when using the Optima 17MS column, but were separable when using the Rxi-5ms column for environmental samples. However, additional samples with different matrix effects should be tested to determine the column type with the best peak separation.

\subsection{Performance of the preparative HPLC procedure}

MurA was the primary target compound when developing the preparative HPLC protocol, because it serves as a specific biomarker for bacteria, but is typically low in abundance in subseafloor sediments (Fig. 1c). ManN, another minor amino sugar, could not be isolated from GlcN and GalN using this approach. Nevertheless, preparative HPLC was beneficial for isotopic analysis of ManN, due to partial removal of the sample matrix, which allowed us to concentrate the sample into a small volume for GC injection. We observed minimal losses of GalN and MurA after preparative HPLC, but recoveries of GlcN and ManN were only 87 and $71 \%$, respectively (Table 3). The F2 and waste fractions contained less than $1 \%$ of the original GlcN and ManN, suggesting that GlcN and ManN were either lost via preferential adsorption in the column, or that derivatization of these two amino sugars was hampered by the presence of ammonium formate originating from the HPLC eluents.

\subsection{Summary of the protocol and isotope data assessment}

Figure 2 summarizes the optimized pretreatment procedure. In brief, amino sugars are released from marine sediments by hot $\mathrm{HCl}$. The hydrolysate then undergoes a series of purification steps, including filtration with combusted glass fiber filters, evaporation under vacuum, neutralization with a $\mathrm{KOH}$ solution, and desalting with a ENVI-Carb ${ }^{\mathrm{TM}}$ Plus SPE cartridge. After freeze-drying overnight, amino sugars in the extract are transformed to ANA derivatives, and further purified by a self-packed silica gel column. The recoveries of the 

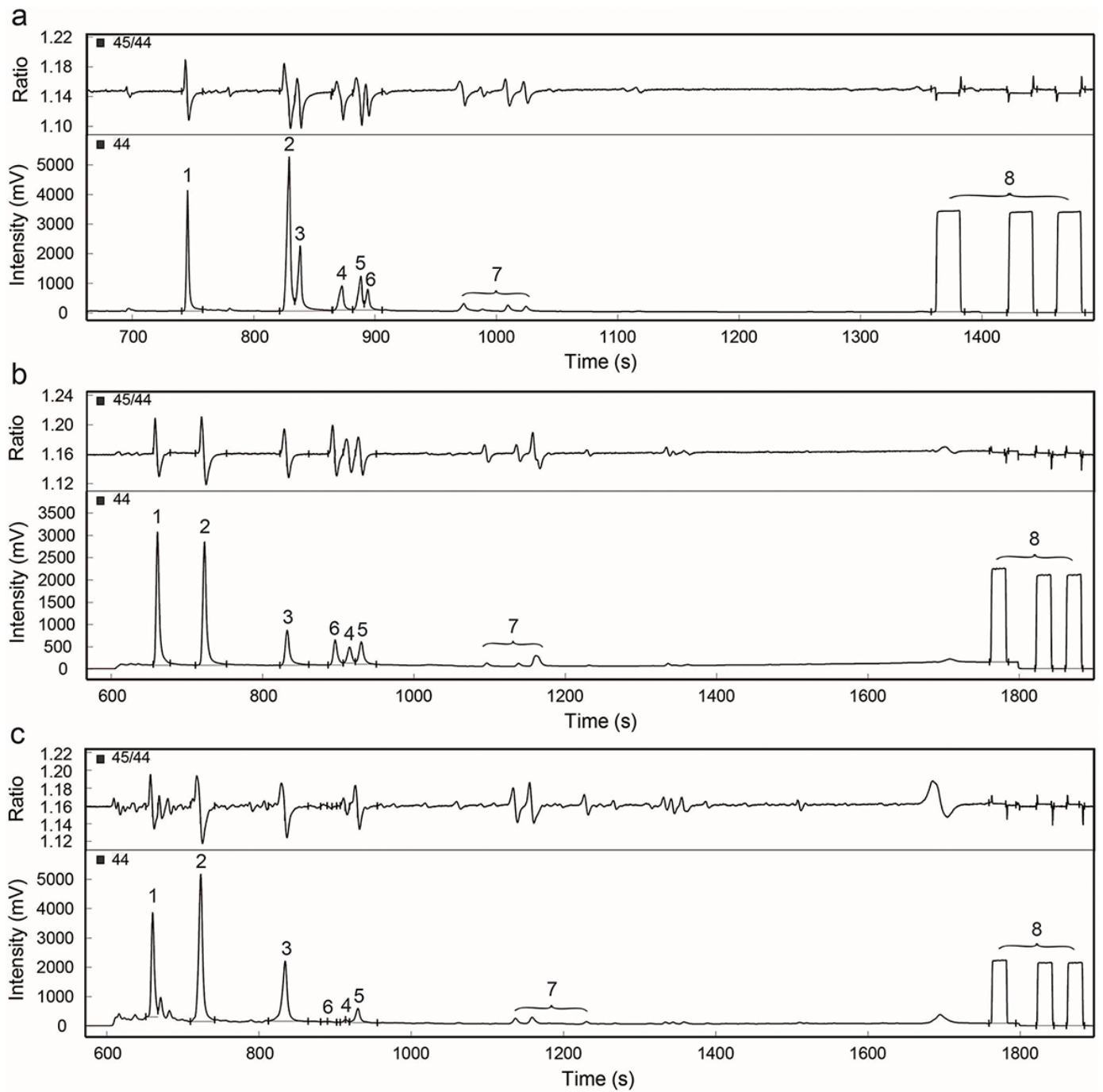

Figure 1. GC-IRMS chromatograms of a standard mixture containing $100 \mathrm{ng}$ of each amino sugar separated by an Rxi-5ms column (a) and an Optima 17MS column (b), respectively, and a marine sediment sample from the Peru Margin separated by an Optima 17MS column (c). Key to peak numbers: aldononitrile derivatives of 3- $O$-methyl-D-glucopyranose (internal standard) (1), myo-inositol (2), glucosamine (3), mannosamine (4), galactosamine (5), muramic acid (6), unknown compounds (7) and reference $\mathrm{CO}_{2}$ gas (8).

whole procedure, estimated from parallel tests $(n=3)$ using a mixture of amino sugar standards, were $111.6 \pm 1.9 \%$, $95.0 \pm 9.2 \%, 47.0 \pm 3.8 \%$ and $102.5 \pm 2.6 \%$ for GlcN, GalN, ManN, and MurA, respectively. The lower recovery of ManN may result from successive preferential losses during each step and is probably related to its steric structure, but the underlying mechanism is not yet fully understood.

It is established that derivatization with acetic anhydride to ANA derivatives is associated with an isotope effect (Glaser and Gross, 2005; Decock et al., 2009); this effect can be corrected with the use of a derivatization standard such as 3$O$-Me-Glc (e.g., Lin et al., 2010). After processing authentic amino sugar standards using our proposed preparation procedure (Fig. 2), and correcting for the isotope effect, the $\delta^{13} \mathrm{C}$ values measured by GC-IRMS $\left(\delta^{13} \mathrm{C}_{\mathrm{AS}}, \mathrm{GC}\right)$ were in good agreement with those obtained by EA-IRMS $\left(\delta^{13} \mathrm{C}_{\mathrm{AS}}\right.$, EA; Table 4), indicating negligible isotopic fractionation during the other sample pretreatment steps. The standard deviations of repeated injections for GC-IRMS were less than $1 \%$, but the total errors were up to $1.4 \%$, i.e., about $1 \%$ greater than those reported for the HPLC-based method developed for soils (Bodé et al., 2009). The total errors, which are derived from the addition of $\mathrm{C}$ atoms and fractionation during derivatization, impose constraints on the isotopic resolving power of our method, and should be taken into account during data interpretation. Despite this disadvantage, the much lower requirement of $\mathrm{C}$ (see below) renders the GC-based method an attractive avenue for the analysis of amino sugars in trace amounts. 
Table 4. $\delta^{13} \mathrm{C}$ values of amino sugar standards analyzed by EA-IRMS $\left(\delta^{13} \mathrm{C}_{\mathrm{AS}}\right.$, EA $)$ or according to the pretreatment procedure described in Fig. 2 prior to GC-IRMS analysis $\left(\delta^{13} \mathrm{C}_{\mathrm{AS}}, \mathrm{GC}\right) . s_{\mathrm{EA}}$ and $s_{\mathrm{GC}}$ stand for standard deviations of EA- or GC-IRMS measurements, respectively. $s_{\text {Total }}$ is the total analytical error of $\delta^{13} \mathrm{C}$ values of individual amino sugars calculated according to the error propagation $(n=3)$.

\begin{tabular}{l|ll|lll}
\hline \multirow{2}{*}{ Compounds } & \multicolumn{2}{|c|}{ EA-IRMS } & \multicolumn{3}{c}{ GC-IRMS } \\
\cline { 2 - 6 } & \multicolumn{2}{|c}{ Pure standard } & \multicolumn{3}{c}{ Hydrolyzed standard } \\
\cline { 2 - 6 } & $\delta^{13} \mathrm{C}_{\mathrm{AS}, \mathrm{EA}}(\% \circ)$ & $s_{\mathrm{EA}}(\% \circ)$ & $\delta^{13} \mathrm{C}_{\mathrm{AS}, \mathrm{GC}}(\% \circ)$ & $s_{\mathrm{GC}}(\% o)$ & $s_{\text {Total }}(\% o)$ \\
\hline $3-O$-Me-Glc & -21.62 & 0.02 & -21.6 & 0.32 & 0.95 \\
Ino & -30.25 & 0.02 & -29.2 & 0.65 & 1.54 \\
GlcN & -20.02 & 0.03 & -19.9 & 0.41 & 1.34 \\
GalN & -20.06 & 0.02 & -20.1 & 0.29 & 1.36 \\
ManN & -20.32 & 0.05 & -20.1 & 0.98 & 1.32 \\
MurA & -20.77 & 0.02 & -20.8 & 0.30 & 0.84 \\
Acetic anhydride & -38.55 & 0.03 & - & - & - \\
\hline
\end{tabular}

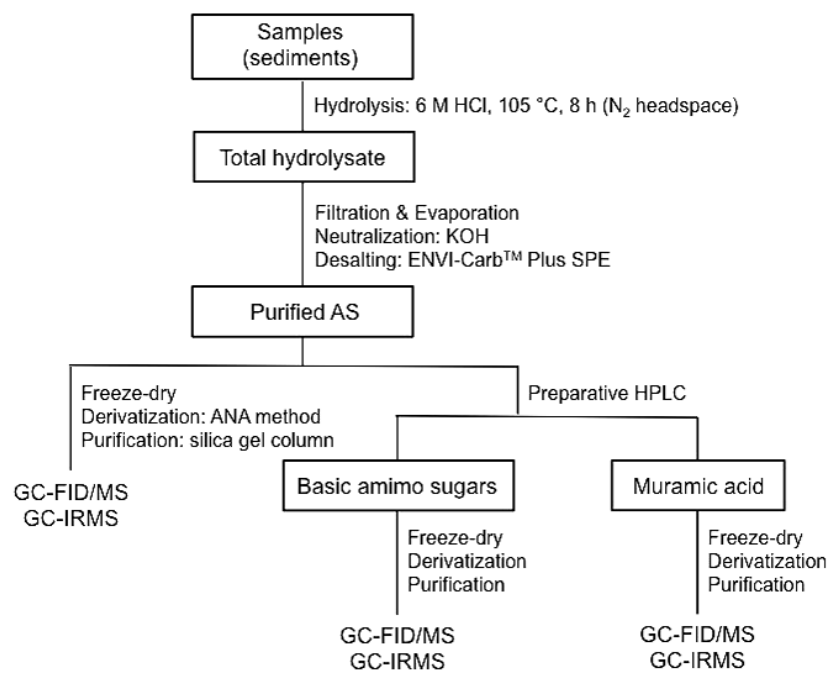

Figure 2. Schematic of the optimized procedure for isotope analysis of amino sugars. Each step has been validated and/or optimized in this study.

For samples that exhibited low signals of MurA and/or ManN due to the high background generated by the sedimentary matrix or a high abundance in the adjacent peak of GalN (i.e., the Peru Margin sample), amino sugar extracts were separated into two fractions (i.e., basic amino sugar fraction and MurA fraction) via the preparative HPLC procedure described above (Fig. 2), which could be further concentrated for GC-IRMS analysis. Tests using authentic amino sugar standards confirmed that this additional step did not introduce significant isotopic fractionation, as the $\delta^{13} \mathrm{C}$ values (Table 3) deviated from those obtained by EA-IRMS (Table 4 ) by less than $0.6 \%$.

The $\delta^{13} \mathrm{C}$ values of ANA derivatives of ManN and MurA were consistent with the EA-IRMS reference values within the range of 20 to $140 \mathrm{ng}$ per injection, i.e., equivalent to $\sim 8-$ $56 \mathrm{ng}$ of amino sugar carbon (Fig. 3), regardless of the pres-
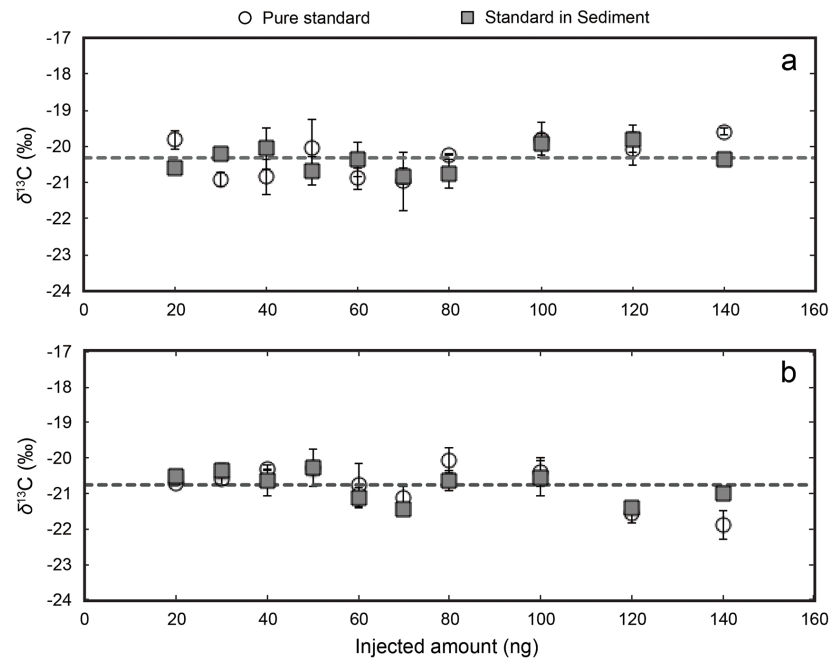

Figure 3. Stable carbon isotopic analysis of $\mathrm{ManN}$ (a) and MurA (b) in a range from 20 to $140 \mathrm{ng}$. Open circles represent the $\delta^{13} \mathrm{C}_{\mathrm{AS}}$, GC values of pure standards. Solid squares designate the $\delta^{13} \mathrm{C}_{\mathrm{AS}}$, GC values of the same standards spiked into sediment extract that did not contain the corresponding amino sugar. The dashed lines are the isotopic values of ManN and MurA determined by EAIRMS, respectively $(n=3)$. The error bars represent the total analytical errors.

ence of a sedimentary matrix; we note that these two amino sugars are usually expected to have the lowest concentration in environmental samples (e.g., Guggenberger et al., 1999; Niggemann and Schubert, 2006; Carsten et al., 2012). At injected quantities below $20 \mathrm{ng}$, the peak height of the respective compound was usually below $100 \mathrm{mV}$, which precluded proper determination of the isotopic composition. The minimum threshold of $20 \mathrm{ng}$ of amino sugar on GC-IRMS is one order of magnitude lower than the values reported for HPLCIRMS (Bodé et al., 2009), and enables the isotopic analysis 


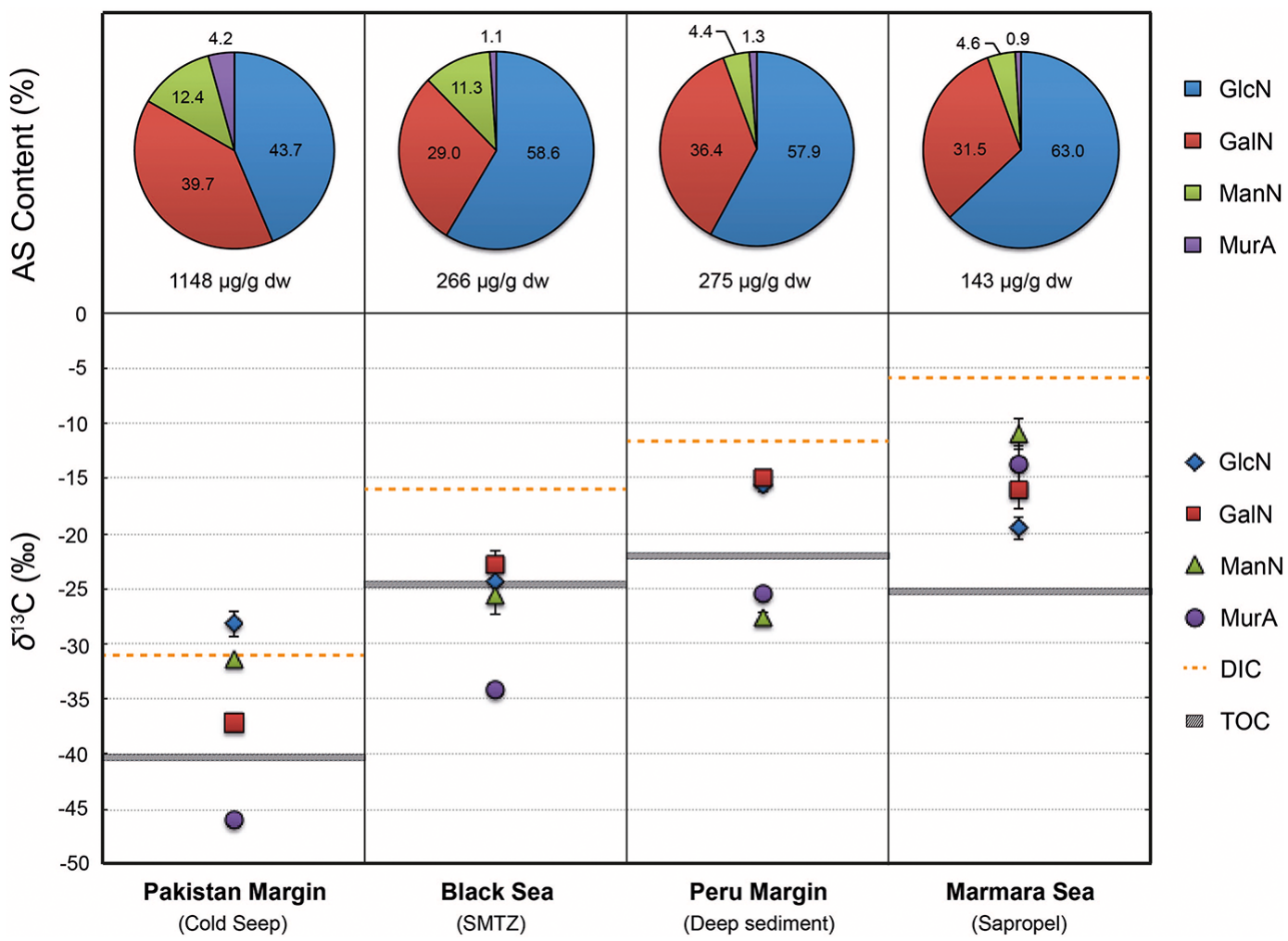

Figure 4. Concentrations and stable carbon isotopic values of amino sugars released from selected marine sediment samples. The depositional settings of the sediment samples are indicated in parentheses. Error bars indicate the total analytical errors $\left(s_{\text {Total }}\right)$ of $\delta^{13} \mathrm{C}$ values of individual amino sugars calculated according to error propagation. The isotopic values of dissolved inorganic carbon (DIC) and total organic carbon (TOC) are also plotted for comparison.

of amino sugars at trace levels, as required by their low abundances in subseafloor sediment.

\subsection{Abundance and isotopic composition of individual amino sugars in marine sediment}

Figure 4 summarizes the concentrations and $\delta^{13} \mathrm{C}$ values of individual amino sugars from four marine sediment samples determined according to the protocol described in Fig. 2. GlcN, accounting for $43.7-63.0 \%$ of the total amino sugars, was the most abundant amino sugar in all the investigated samples, followed by GalN (29.0-39.7\%) and ManN (4.4-12.4\%), while MurA was always less than $5 \%$. The $\delta^{13} \mathrm{C}$ values of GlcN and GalN were similar, and fell between $\delta^{13} \mathrm{C}_{\text {TOC }}$ and $\delta^{13} \mathrm{C}_{\text {DIC }}$ in sediment collected from the Black Sea, the Marmara Sea, and the Peru Margin. In the cold seep sample from the Pakistan Margin, GalN was depleted in ${ }^{13} \mathrm{C}$ by $9 \%$ compared to GlcN. This sample was collected from a microbial mat composed of anaerobic methanotrophic archaea (ANME) group 2 and associated bacterial partners (Yoshinaga et al., 2012). These organisms were likely the predominant sources of TOC in the seep sample, which also exhibited the lowest $\delta^{13} \mathrm{C}_{\mathrm{TOC}}(-40.0 \%$ o). ManN exhibited $\delta^{13} \mathrm{C}$ values ranging from -31.5 to $-10.9 \%$, and showed no consistent trend relative to $\delta^{13} \mathrm{C}_{\mathrm{TOC}}$ and $\delta^{13} \mathrm{C}_{\mathrm{DIC}}$, or to the other amino sugars. MurA spanned the widest range in ${ }^{13} \mathrm{C}$ (from -46.0 to $-13.6 \%$ ), and was more depleted than $\delta^{13} \mathrm{C}_{\mathrm{TOC}}$ in the Pakistan Margin, Black Sea, and Peru Margin samples.

GlcN and GalN are typically the major amino sugars found in sediment and preserved in the form of peptidoglycan, lipopolysaccharides, and pseudopeptidoglycan from prokaryotes (Schleifer and Kandler, 1972; Kandler et al., 1998; Madigan and Martinko, 2005). Moreover, GlcN has also been detected in most fungal cell walls and invertebrate exoskeletons as chitin (Müller et al., 1986; Liang et al., 2007; Davis et al., 2009). It is generally believed that the basic amino sugars persist after cell death, and are stable in soils (Glaser et al., 2004). Assuming a similar behavior in marine sediment, these amino sugars are likely derived from a diverse assemblage of pelagic and sedimentary organisms, and have been preserved in the sediment. The lack of a significant discrepancy between the $\delta^{13} \mathrm{C}$ values of GlcN and GalN (usually <3.5\%o) implies a common, likely allochthonous source in the Black Sea, Marmara Sea, and Peru Margin sediments. The distinct isotopic compositions of GlcN $(-28.2 \%)$ and GalN $(-37.2 \% o)$ in the Pakistan Margin cold seep sample can be explained best by an increasing 
fraction of these amino sugars from autochthonous microbes that utilize ${ }^{13} \mathrm{C}$-depleted carbon for biosynthesis, as is known from other biomolecules at similar sites (e.g., Lin et al., 2010; Schubotz et al., 2011). Further application of this method to define the heterogeneity of $\delta^{13} \mathrm{C}$ signatures of individual hexosamines in the downcore sediment profiles will help additionally to examine microbial activity in specific sediment horizons.

In contrast to the basic amino sugars with their diverse origins, MurA is a diagnostic bacterial biomarker, because it is exclusively derived from peptidoglycan in bacterial cell walls (Schleifer and Kandler, 1972), and is presumed to degrade rapidly after cell death (Moriarty, 1977). The relatively high abundance of MurA (4.2\% of total amino sugars) and its strong ${ }^{13} \mathrm{C}$ depletion $\left({ }^{13} \mathrm{C}\right.$ of $-46.0 \%$ o in the Pakistan Margin sample are consistent with our expectations of cold seep sediment that hosts microbial biomass fueled by methane (Hinrichs et al., 1999). Likewise, the ${ }^{13} \mathrm{C}$-depleted MurA in the Black Sea sample is probably an indigenous signal resulting from bacteria that utilize relatively ${ }^{13} \mathrm{C}$-depleted carbon at this depth $(1.57 \mathrm{mbsf})$, which is close to the sulfatemethane transition zone, based on this site's methane profile (Zabel et al., 2013). Although compound-specific isotopic analysis of amino sugars is more demanding than that of membrane lipids, these observations of putative indigenous bacterial signals in the form of MurA make this compound a valuable biomarker target for the isotopic analysis of microbial biomass in the deep marine biosphere, which so far has been based on lipids and intact cells, and biased towards detection of signals of the Archaea (cf. Biddle et al., 2006). The combined analysis of hydrolysable sugar-derived biomarkers with lipid biomarkers, with each group derived from different biosynthetic pathways and representing different preservation mechanisms, holds great potential for providing a more balanced view for the study of microbial life in subseafloor sediments.

\section{Conclusion}

Methods for the carbon isotopic analysis of amino sugars have been developed for soils, but not for marine sediments, where amino sugar concentrations tend to be lower. We tested various steps in the workflow of amino sugar analysis in order to establish a robust protocol for the stable carbon isotopic analysis of amino sugars in marine sediments. A combination of the most effective steps, including a new SPE protocol for the post-hydrolysis clean-up and a new step for enrichment of amino sugars via preparative HPLC, resulted in a protocol optimized for GC-based isotopic analysis of amino sugars at trace levels (the limit of detection is $20 \mathrm{ng}$, equivalent to $\sim 8 \mathrm{ng}$ of amino sugar $\mathrm{C}$ ). The conversion of amino sugars to ANA derivatives results in GC-amenable analytes that have long-term stability and are suitable for isotopic analysis. Moreover, use of the protocol did not introduce sig- nificant isotopic fractionation during sample preparation, except for the derivatization step, which can be accounted for with a derivatization standard. Applying this protocol, we determined for the first time the carbon isotopic composition of amino sugars in marine sediment samples. The stable carbon isotopic values of basic amino sugars indicated a major contribution from organic detritus, whereas MurA was more sensitive to an indigenous and active bacterial community. This method thus enables investigation of the stable carbon isotopic compositions of amino sugars, and provides a valuable addition to the lipid-based characterization of microbial metabolism in the deep marine biosphere.

Acknowledgements. Samples were retrieved from a field trip to the Wadden Sea (Germany), during RV Meteor cruises M74/3 and M84/1 (DARCSEAS), and leg 201 of the Ocean Drilling Program (ODP), which is sponsored by the US National Science Foundation and participating countries under the management of Joint Oceanographic Institutions (JOI), Inc. We thank the participating scientists and ship crews for sample recovery, Marcus Elvert and Marcos Yoshinaga for valuable advice and discussions, and Jessica Arndt, Raika Himmelsbach, Xavier Prieto Mollar and Jenny Wendt for technical assistance. This study was primarily supported by the Deutsche Forschungsgemeinschaft (DFG) through grant HI 616/11-1 (Cell Surf) to K.-U. Hinrichs. R. Zhu was sponsored by the China Scholarship Council (CSC) and the Gottfried Wilhelm Leibniz Program of the DFG (through the Leibniz Prize to K.-U. Hinrichs).

Edited by: T. Treude

\section{References}

Aluwihare, L. I. and Meador, T. B. (Eds.): Chemical composition of marine dissolved organic nitrogen, in: Nitrogen in the Marine Environment, Elsevier, Oxford, UK, 95-140, 2008.

Aluwihare, L. I., Repeta, D. J., Pantoja, S., and Johnson, C. G.: Two chemically distinct pools of organic nitrogen accumulate in the ocean, Science, 308, 1007-1010, 2005.

Amelung, W., Cheshire, M. V., and Guggenberger, G.: Determination of neutral and acidic sugars in soil by capillary gas-liquid chromatography after trifluoroacetic acid hydrolysis, Soil Biol. Biochem., 28, 1631-1639, 1996.

Amelung, W., Zhang, X., Flach, K. W., and Zech, W.: Amino sugars in native grassland soils along a climosequence in North America, Soil Sci. Soc. Am. J., 63, 86-92, 1999.

Amelung, W. (Ed.): Methods using amino sugars as markers for microbial residues in soil, in: Assessment Methods for Soil Carbon, Lewis Publishers, Boca Raton, FL, 233-272, 2001.

Bai, Z., Bode, S., Huygens, D., Zhang, X., and Boeckx, P.: Kinetics of amino sugar formation from organic residues of different quality, Soil Biol. Biochem., 57, 814-821, 2012.

Benner, R. and Kaiser, K.: Abundance of amino sugars and peptidoglycan in marine particulate and dissolved organic matter, Limnol. Oceanogr., 48, 118-128, 2003.

Biddle, J. F., Lipp, J. S., Lever, M. A., Lloyd, K. G., Sørensen, K. B., Anderson, R., Fredricks, H. F., Elvert, M., Kelly, T. J., 
Schrag, D. P., Sogin, M.L., Brenchley, J. E., Teske, A., House, C. H., and Hinrichs K.-U.: Heterotrophic Archaea dominate sedimentary subsurface ecosystems off Peru, Proc. Natl. Acad. Sci. USA, 103, 3846-3851, 2006.

Bodé, S., Denef, K., and Boeckx, P.: Development and evaluation of a high-performance liquid chromatography/isotope ratio mass spectrometry methodology for ${ }^{13} \mathrm{C}$ analyses of amino sugars in soil, Rapid Commun. Mass Spectrom., 23, 2519-2526, 2009.

Çağatay, M., Görür, N., Algan, O., Eastoe, C., Tchapalyga, A., Ongan, D., Kuhn, T., and Kuşcu, İ.: Late Glacial-Holocene palaeoceanography of the Sea of Marmara: timing of connections with the Mediterranean and the Black Seas, Mar. Geol., 167, 191-206, 2000.

Carstens, D., Köllner, K. E., Bürgmann, H., Wehrli, B., and Schubert, C. J.: Contribution of bacterial cells to lacustrine organic matter based on amino sugars and D-amino acids, Geochim. Cosmochim. Acta, 89, 159-172, 2012.

Cowie, G. L. and Hedges, J. I.: Determination of neutral sugars in plankton, sediments, and wood by capillary gas chromatography of equilibrated isomeric mixtures, Anal. Chem., 56, 497-504, 1984.

Davis, J., Kaiser, K., and Benner, R.: Amino acid and amino sugar yields and compositions as indicators of dissolved organic matter diagenesis, Org. Geochem., 40, 343-352, 2009.

Decock, C., Denef, K., Bodé, S., Six, J., and Boeckx, P.: Critical assessment of the applicability of gas chromatographycombustion-isotope ratio mass spectrometry to determine amino sugar dynamics in soil, Rapid Commun. Mass Spectrom., 23, 1201-1211, 2009.

Dippold, M. A., Boesel, S., Gunina, A., Kuzyakov, Y., and Glaser, B.: Improved $\delta^{13} \mathrm{C}$ analysis of amino sugars in soil by ion chromatography-oxidation-isotope ratio mass spectrometry, Rapid Commun. Mass Spectrom., 28, 569-576, 2014.

Fischer, D., Sahling, H., Nöthen, K., Bohrmann, G., Zabel, M., and Kasten, S.: Interaction between hydrocarbon seepage, chemosynthetic communities, and bottom water redox at cold seeps of the Makran accretionary prism: insights from habitatspecific pore water sampling and modeling, Biogeosciences, 9, 2013-2031, doi:10.5194/bg-9-2013-2012, 2012.

Fox, A., Morgan, S. L., Hudson, J. R., Zhu, Z. T., and Lau, P. Y.: Capillary gas chromatographic analysis of alditol acetates of neutral and amino sugars in bacterial cell walls, J. Chromatogr. A, 256, 429-438, 1983.

Fox, A., Wright, L., and Fox, K.: Gas chromatography-tandem mass spectrometry for trace detection of muramic acid, a peptidoglycan chemical marker, in organic dust, J. Microbiol. Methods, 22, 11-26, 1995.

Fox, A., Krahmer, M., and Harrelson, D.: Monitoring muramic acid in air (after alditol acetate derivatization) using a gas chromatograph-ion trap tandem mass spectrometer, J. Microbiol. Methods, 27, 129-138, 1996.

Glaser, B., Turrión, M., and Alef, K.: Amino sugars and muramic acid-biomarkers for soil microbial community structure analysis, Soil Biol. Biochem., 36, 399-407, 2004.

Glaser, B. and Gross, S.: Compound-specific $\delta^{13} \mathrm{C}$ analysis of individual amino sugars - a tool to quantify timing and amount of soil microbial residue stabilization, Rapid Commun. Mass Spectrom., 19, 1409-1416, 2005.
Guerrant, G. and Moss, C.: Determination of monosaccharides as aldononitrile, O-methyloxime, alditol, and cyclitol acetate derivatives by gas chromatography, Anal. Chem., 56, 633-638, 1984.

Guggenberger, G., Frey, S., Six, J., Paustian, K., and Elliott, E.: Bacterial and fungal cell-wall residues in conventional and no-tillage agroecosystems, Soil Sci. Soc. Am. J., 63, 1188-1198, 1999.

Hinrichs, K.-U., Hayes, J. M., Sylva, S. P., Brewer, P. G., and DeLong, E. F.: Methane-consuming archaeabacteria in marine sediments, Nature, 398, 802-805, 1999.

Itoh, S., Kawasaki, N., Ohta, M., and Hayakawa, T.: Structural analysis of a glycoprotein by liquid chromatography-mass spectrometry and liquid chromatography with tandem mass spectrometry: Application to recombinant human thrombomodulin, J. Chromatogr. A, 978, 141-152, 2002.

Kandler, O. and König, H.: Cell wall polymers in Archaea (Archaebacteria), Cell Mol. Life Sci., 54, 305-308, 1998.

Kellermann, M. Y., Wegener, G., Elvert, M., Yoshinaga, M. Y., Lin, Y.-S., Holler, T., Mollar, X. P., Knittel, K., and Hinrichs, K.-U.: Autotrophy as a predominant mode of carbon fixation in anaerobic methane-oxidizing microbial communities, Proc. Natl. Acad. Sci. USA, 109, 19321-19326, 2012.

Langerhuus, A. T., Røy, H., Lever, M. A., Morono, Y., Inagaki, F., Jørgensen, B. B., and Lomstein, B. A.: Endospore abundance and $\mathrm{d}$ : 1-amino acid modeling of bacterial turnover in holocene marine sediment (Aarhus Bay), Geochim. Cosmochim. Acta, 99, 87-99, 2012.

Liang, C., Zhang, X., and Balser, T. C.: Net microbial amino sugar accumulation process in soil as influenced by different plant material inputs, Biol. Fertil. Soils, 44, 1-7, 2007.

Lin, Y.-S., Lipp, J. S., Yoshinaga, M. Y., Lin, S. H., Elvert, M., and Hinrichs, K.-U.: Intramolecular stable carbon isotopic analysis of archaeal glycosyl tetraether lipids, Rapid Commun. Mass Spectrom., 24, 2817-2826, 2010.

Lin, Y.-S., Lipp, J. S., Elvert, M., Holler, T., and Hinrichs, K.U.: Assessing production of the ubiquitous archaeal diglycosyl tetraether lipids in marine subsurface sediment using intramolecular stable isotope probing, Environ. Microbiol., 15, 1634-1646, 2013.

Lomstein, B. A., Langerhuus, A. T., D’Hondt, S., Jørgensen, B. B., and Spivack, A. J.: Endospore abundance, microbial growth and necromass turnover in deep sub-seafloor sediment, Nature, 484, 101-104, 2012.

Madigan, M. T. and Martinko, J. M. (Eds.): Brock Biology of Microorganisms 11th edn., Prentice Hall, Upper Saddle River, USA, 2005.

McCullagh, J. S. O.: Mixed-mode chromatography/isotope ratio mass spectrometry, Rapid Commun. Mass Spectrom., 24, 483494, 2010.

Moriarty, D.: Improved method using muramic acid to estimate biomass of bacteria in sediments, Oecologia, 26, 317-323, 1977.

Morrison, D. J., Taylor, K., and Preston, T.: Strong anion-exchange liquid chromatography coupled with isotope ratio mass spectrometry using a Liquiface interface, Rapid Commun. Mass Spectrom., 24, 1755-1762, 2010.

Müller, P. J., Suess, E., and André Ungerer, C.: Amino acids and amino sugars of surface particulate and sediment trap material from waters of the Scotia Sea, Deep Sea Res., 33, 819-838, 1986. 
Neeser, J. and Schweizer, T.: A quantitative determination by capillary gas-liquid chromatography of neutral and amino sugars (as O-methyloxime acetates), and a study on hydrolytic conditions for glycoproteins and polysaccharides in order to increase sugar recoveries, Anal. Biochem., 142, 58-67, 1984.

Niggemann, J. and Schubert, C.: Sources and fate of amino sugars in coastal Peruvian sediments, Geochim. Cosmochim. Acta, 70, 2229-2237, 2006.

Quaiser, A., Zivanovic, Y., Moreira, D., and López-García, P.: Comparative metagenomics of bathypelagic plankton and bottom sediment from the Sea of Marmara, ISME J., 5, 285-304, 2010.

Rinne, K. T., Saurer, M., Streit, K., and Siegwolf, R. T. W.: Evaluation of a liquid chromatography method for compound-specific $\delta^{13} \mathrm{C}$ analysis of plant carbohydrates in alkaline media, Rapid Commun. Mass Spectrom., 26, 2173-2185, 2012.

Schleifer, K. and Kandler, O.: Peptidoglycan types of bacterial cell walls and their taxonomic implications, Bacteriol. Rev., 36, 407477, 1972.

Schubotz, F., Lipp, J. S., Elvert, M., and Hinrichs, K.-U.: Stable carbon isotopic compositions of intact polar lipids reveal complex carbon flow patterns among hydrocarbon degrading microbial communities at the Chapopote asphalt volcano, Geochim. Cosmochim. Acta, 75, 4399-4415, 2011.
Simpson, R. T., Frey, S. D., Six, J., and Thiet, R.K.: Preferential accumulation of microbial carbon in aggregate structures of notillage soils, Soil Sci. Soc. Am. J., 68, 1249- 1255, 2004.

Veuger, B., van Oevelen, D., Boschker, H. T. S., and Middelburg, J. J.: Fate of peptidoglycan in an intertidal sediment: An in situ ${ }^{13}$ C-labeling study, Limnol. Oceanogr., 51, 1572-1580, 2006.

Yoshinaga, M. Y., Wörmer, L., Elvert, M., and Hinrichs, K.-U.: Novel cardiolipins from uncultured methane-metabolizing $\mathrm{Ar}$ chaea, Archaea, 2012, 1-9, doi:10.1155/2012/832097, 2012.

Zabel, M. and cruise participants: RV METEOR, Cruise Report M84/L1, Biogeochemistry and methane hydrates of the Black Sea; Oceanography of the Mediterranean; shelf sedimentation and cold water carbonates 2011, DFG Senatskommission für Ozeanographie, 39 pp., 2013.

Zhang, X. and Amelung, W.: Gas chromatographic determination of muramic acid, glucosamine, mannosamine, and galactosamine in soils, Soil Biol. Biochem. 28, 1201-1206, 1996.

Zhang, X., Amelung, W., Yuan, Y., Samson-Liebig, S., Brown, L., and Zech, W.: Land-use effects on amino sugars in particle size fractions of an Argiudoll, Appl. Soil Ecol., 11, 271-275, 1999. 